\title{
Belirtisiz ad tamlaması biçiminde oluşan birleşik sözcüklerin yazımında meydana gelen dil bilgisel aykırılıklar
}

\section{Soner TOKTAR 1}

\begin{abstract}
APA: Toktar, S. (2019). Belirtisiz ad tamlaması biçiminde oluşan birleşik sözcüklerin yazımında meydana gelen dil bilgisel aykırılıklar. RumeliDE Dil ve Edebiyat Araştırmaları Dergisi, (14), 24-32. DOI: $10.29000 /$ rumelide.540992
\end{abstract}

$\ddot{O} \mathbf{z}$

Dil dizgesi yeni kavramları adlandırmak için çeşitli yöntemler kullanır. Birleşik sözcük oluşturma yöntemi, dildeki yeni kavramları adlandırmada kullanılan yöntemlerden biridir. Tek bir kavramı işaret etmeleri yönüyle belirtisiz ad tamlamaları birleşik sözcük oluşturmaya müsait yapılardır ve Türkçede bu yolla oluşmuş birleşik sözcüklere sıkça rastlanır (ayakkabı, binbaşı, hanımeli, Beypazarı vb.). Belirtisiz ad tamlaması biçiminde oluşan birleşik sözcüklerin bazılarında tamlama özelliği ortadan kalkarken, bazılarında tamlama özelliği devam etmektedir. Tamlama özelliğini devam ettiren birleşik sözcükleri bitişik yazmak çeşitli dil bilgisel sorunları da beraberinde getirmektedir. Birleşik sözcük halini aldığı için bitişik yazılması gerektiği düşünülen bu gibi yapılara çokluk, iyelik, hâl gibi ad çekim ekleri getirildiğinde Türkçe dil bilgisi kurallarına aykırı durumlar ortaya çıkmaktadır. Bu aykırılıklar da, belirtisiz ad tamlaması biçiminde oluşmuş bazı birleşik sözcüklerin, tamlama özelliklerini henüz kaybetmediklerini düşündürmektedir. Türk Dil Kurumu'nun 2012 yılında yayımladığı en son Yazım Kılavuzu’na bakıldığında birleşik sözcüklerin bitişik veya ayrı yazılmalarında dikkate alınacak temel kuralın ses veya anlam değişmeleri olduğu görülür. Bununla birlikte Kılavuz'da yer alan bazı açıklamalar birbiriyle çelişmektedir. Ayrıca tamlama özelliğini yitirmemiş birleşik sözcüklerin yazımına dair herhangi bir açılama yapılmamıştır. Bu çalışmada birleşik sözcükler hakkında kısaca bilgi verilip bu sözcüklerin yazımına dair farklı araştırmacıların görüşlerine yer verilecek, belirtisiz ad tamlaması biçiminde oluşmuş birleşik sözcükler üzerinde durulacak ve buradan hareketle, tamlama özelliğini devam ettiren birleşik sözcüklerin yazımında meydana gelen dil bilgisel aykırılıklar ortaya konacaktır.

Anahtar kelimeler: Belirtisiz ad tamlaması, birleşik sözcük, yazım, dil bilgisi.

\section{The grammatical contradictions in the writing of the compound words that formed in the form of indeterminative noun phrase}

\begin{abstract}
The language system uses several methods to name new concepts. The method of compound word creation is one of the methods used to name new concepts in language. In the direction of pointing to a single concept, indeterminative noun phrases are structures that are suitable for compound words. In Turkish, compound words formed in this way are frequently encountered (ayakkabl, binbaşı, hantmeli, Beypazarl etc.). In some of the compound words that formed in the form of indeterminative noun phrase, the noun phrase emphasis is eliminated, while in some of them the emphasis continues. Various grammatical problems arise in the writing of compound words that maintain the emphasis. When inflectional suffixes are added to such structures, there are cases where

1 Arş. Gör., Kırklareli Üniversitesi, Fen Edebiyat Fakültesi, Türk Dili ve Edebiyatı Bölümü, (Kırklareli, Türkiye), so_near91@hotmail.com, ORCID ID: oooo-0o01-8435-4233 [Makale kayıt tarihi: 24.01.2019-kabul tarihi: 14.03.2019; DOI: $10.29000 /$ rumelide.540992]
\end{abstract}




\begin{abstract}
Turkish grammar rules are violated. These contradictions suggest that these structures did not lose their emphasis. When we look at the most recent Spelling Guide published by the Turkish Language Association in 2012, it is seen that the basic rule to be taken into account in the adjacent or separate writing of the compound words is phonetic or semantic change. However, some of the explanations in the Spelling Guide contradict each other. In addition, no explanation has been made about the writing of compound words that maintain the emphasis of noun phrase. In this study, we will give brief information about the compound words and the opinions of different researchers about the writing of these words. Compound words formed in the form of indeterminative noun phrase will be elaborated, and, from this point on, the grammatical contradictions in the writing of the compound words that continue to emphasize the noun phrase will be revealed.
\end{abstract}

Key words: Indeterminative noun phrase, compound word, writing, grammar.

\title{
Giriş
}

İnsanın zihnindeki bir dizge olarak tasavvur edilen dil, insanı diğer canlılardan ayıran en önemli özelliktir. İnsan dil sayesinde düşünmekte, düşüncesini ifade etmekte, başkalarıyla iletişim kurabilmekte, nesneleri ve olguları adlandırarak yaşadığı dünyaya düzen getirmektedir. Bir dizge olması yönüyle dil, birbiriyle bağlantılı sınırlı sayıda alt dizgeden oluşmaktadır. Sınırlı sayıda kuralları olan dil dizgesi bu kurallardan hareketle sınırsız sayıda ifade üretebilme olanağına sahiptir. Zamanın şartları değiştikçe insanların hayatına yeni nesneler ve kavramlar girmeye başlar. İnsan, zihnindeki bu dil dizgesini kullanarak hayatına giren yeni nesne ve kavramları adlandırma yoluna gider. Örneğin bundan yüz yıl öncesinde insanların hayatında bilgisayar adı verilen nesne henüz yokken zamanla bu nesnenin icat edilmesiyle birlikte ona bir ad verme gereği de doğmuştur. Türkçe bu nesneye ad vermek için kendi dil dizgesindeki kurallardan hareket etmiş ve bu yeni nesnenin zihinde oluşturduğu kavramı adlandırmıştır. Dil, insan ve toplum hayatına giren yeni kavramları adlandırmak için çeşitli yöntemler kullanır. Türkçe de tıpkı diğer tüm dillerde olduğu gibi, yeni kavramları adlandırma konusunda çeşitli yöntemlere başvurur. Türetme, birleştirme, yabancı dilden alma, kısaltma vb. yöntemler yeni kavramları adlandırmada kullanılan yöntemlerden bazılarıdır. Türkçe, yeni kavramları adlandırmada birleşik sözcük oluşturma/birleştirme yöntemini sıklıkla kullanır.

\section{Birleşik sözcükler}

Birleşik sözcüğü Korkmaz "yeni bir kavramı karşılamak için iki veya daha çok kelimenin Türkçenin söz kalplarına uygun belirli yollarla bir araya getirilmesi ile kurulmuş söz birliği (Korkmaz, 1992, s. 27)"; Ergin "herhangi bir kelime grubunun kelimelerinin tek bir kelime halinde birleşmesiyle ortaya çıkan unsur (Ergin, 2009, s. 385)”; İmer, Kocaman \& Özsoy “iki ya da daha çok sözcüğün dilin kuralları doğrultusunda bir araya gelmesi ve kahplaşmasıyla oluşup anlaml tek bir birim işlevi gören, anlamı kendini oluşturan sözcüklerin anlamından bağımsız bir sözlüksel birim niteliği taşıyan dizim (İmer, Kocaman, \& Özsoy, 2011, s. 56)" ve Karaağaç “bir kavram ya da nesneyi karşılamak amactyla, anlam değerlerini yitiren iki veya daha çok sözün birleştirilmesi ile oluşturulan yeni sözler (Karaağaç, Dil Bilimi Terimleri Sözlüğü, 2013, s. 207)” şeklinde tanımlamışlardır. Dilde yeni kavramları adlandırmak için türetme, birleştirme, kısaltma, yabancı dilden alma vb. yöntemler kullanılır. Birleşik sözcükler birleştirme yöntemiyle oluşmaktadır. Birleşmenin sözcük türetiminden farkına değinen Banguoğlu'nda şu ifadeler yer alır: "Üretimde birleşenlerden yalnız biri, taban, müstakil anlam taşır, ek o anlamda değişiklik yapan bir unsurdur. Birleşimde ise iki kelime önceden ayrı anlamlar taşırlar. Bunların tek 
The grammatical contradictions in the writing of the compound words that formed in the form of Indeterminative noun phrase / S. Toktar (p. 24-32)

kelime gibi ayrılmaz bir tek kavramı karşılayacak şekilde kaynaşması birleşik kelimeyi meydana getirir (Banguoğlu, 2015, s. 294)”.

Birleşik sözcükler birleşik adlar ve birleşik fiiller olmak üzere iki türlüdür. Birleşik adlar çeşitli yollarla oluşabilmektedir. Korkmaz, oluşum türlerine göre birleşik adları dört başlık altında ele almaktadır:

1. Ad+ad yapısındaki birleşik adlar (Abdülhak Şinasi Hisar, Ahmet Hikmet Müftüoğlu vb.),

2. Ad tamlaması kalıbındaki birleşik adlar (aslanağzı, ayakkabı, kuş gagası, külhanbeyi, adamın zoru, elinin körü vb.),

3. Sıfat tamlaması kalıbındaki birleşik adlar (açıgöz, başkent, kılkuyruk, kara sevda vb.),

4. Öteki kelime grupları ve cümle biçimindeki birleşik adlar (gecekondu, imambayldı, mirasyedi, Erol, Seval vb.) (Korkmaz, 2014, s. 260-266).

Bunların içinde birleşik sözcük oluşturmada en sık kullanılanı ise ad tamlamalarıdır.

\section{Belirtisiz ad tamlaması biçiminde oluşmuş birleşik sözcükler}

Ad tamlamaları, iki veya daha fazla adın çeşitli dil bilgisel yollarla bir araya gelerek ortak bir anlam ilişkisi ortaya koydukları oluşumlardır. Ad tamlamalarında tamlayan ve tamlanan olmak üzere iki unsur bulunmaktadır. Ad tamlamasını oluşturan öğelerin ilgi (tamlayan) veya iyelik (tamlanan) eki alıp almamalarına göre tamlama farklı şekillerde adlandırılmaktadır. Tamlayanı eksiz, yalın durumda bulunan, tamlananı teklik üçüncü şahıs iyelik eki alan, yani belirti eki almayan ad tamlaması (Korkmaz, 1992, s. 23) belirtisiz ad tamlaması olarak adlandırılır. Belirtisiz ad tamlamalarında bir araya gelen iki adın tek bir kavramı işaret ettiği görülür. Belirtili ad tamlamalarında ise ilgi (belirlilik) ekini almış olan tamlayan vurgulu ve belirli olduğu için tamlamayı oluşturan her iki unsur da ayrı ayrı anlamlarını korur. Bu durum da belirtili ad tamlamalarının tek bir kavramı işaret etmelerine engel olur. Evin kapısı gibi bir tamlamada hem ev hem de kapı adları zihinde çağrışım yapmaktadır. Ancak ev kapısı gibi bir tamlamada zihinde oluşan kavram tektir. Bu sebeple, belirtisiz ad tamlamaları zaman içerisinde kalıplaşarak birleşik sözcük oluşturmaya çok müsaittir ve Türkçede bu şekilde oluşmuş birleşik sözcükler geniş yer tutmaktadır (ayakkabı, Adapazarı, başörtüsü, kahverengi, çörekotu, kapıkulu, yüzbaşı vb.).

Belirtili ve belirtisiz ad tamlamalarının farklarına değinerek, bu tamlamaların birleşik sözcük oluşturmasıyla ilgili Ediskun şu ifadelere yer verir:
"Belirtili isim takımlarında belirtenin belirtilenle ilgisi ve bağlantısı geçicidir. Bu nedenle, bir belirtili isim takımında öğelerin kaynaşmasıyla oluşmuş bileşik kelimelerimiz yoktur. (...) Belirtisiz isim takımlarında belirtenin belirtilenle ilgisi ve bağlantısı süreklidir, sıkıdır. Hemen hemen bütün belirtisiz isim takımları, bileşik kelime olmaya hazırdırlar. Bu nedenle, belirtisiz isim takımlarıyla yapılmış bileşik kelimelerimiz pek çoktur (Ediskun, 2017, s. 120)".

Belirtisiz ad tamlamalarının birleşik sözcük oluşturmasına çok sık rastlanmakla birlikte belirtili ad tamlamalarında da istisnai olarak bu durum görülebilmektedir. Belirtili ad tamlaması, bilinen belirli bir adı, aitlik bağı ile pekiştiren bir ad türü olduğu için (annemin çantası, evin kapısı), yeni bir kavrama karşllık olan birleşik ada dönüşmeye elverişli değildir. Bununla birlikte abartmalı anlatımdan kaynaklanan bu yapıda bazı deyimleşmiş adlar da vardır: adamın zoru, devenin başı, elinin körü, Allahın günü, malın gözü gibi (Korkmaz, 2014, s. 262). 
Görüldüğü gibi birleşik sözcükler dilde yeni kavramları adlandırmada önemli işleve sahiptir. Ad tamlamaları da birleşik sözcük oluşturmaya en uygun yapılardandır. Özellikle belirtisiz ad tamlamaları Türkçede birçok birleşik sözcük oluşturmuştur. Ancak Türkçede bu yolla oluşmuş birleşik sözcüklerden bazılarının, tamlama özelliklerini kaybedip kaybetmediği ve bitişik olarak yazılmasının doğru olup olmadığı konusunun ele alınması gerekmektedir. Bu konuya girmeden önce, birleşik sözcüklerin yazımı ile ilgili farklı görüşleri vermek yararlı olacaktır.

\section{Birleşik sözcüklerin yazımı ile ilgili görüşler}

Birleşik sözcüklerin yazımı uzun süredir tartışılmakta olan ve kesin çözüme kavuşamayan bir meseledir. Bu konu çeşitli dil bilgisi kitaplarında ve müstakil makalelerde ele alınmış, araştırmacılar farklı öneriler sunmuştur.

Türkçenin dil bilgisi üzerine yazılmış çeşitli eserlere bakıldığında genel görüş olarak birleşik sözcüklerin bitişik yazılması gerektiği ifade edilmiştir. Ergin, birleşik sözcüklerin bitişik olarak yazılması ve bunların tek bir sözcük olarak düşünülmesi gerektiğini, ayrı yazılmaları halinde onları meydana getiren grup (ad tamlaması, sıfat tamlaması ya da diğer öbekler) olduklarını (Ergin, 2009, s. 386); Banguoğlu, bitişik veya ayrı yazma meselesinin göreceli olduğunu, bu sözcüklerin bazı dillerde bitişik bazı dillerde ayrı yazıldığını, tamlamaları sıklıkla kullanan Türkçenin ise bu sözcükleri bitişik yazma eğiliminde olduğunu (Banguoğlu, 2015, s. 296); Gencan birleşik sözcükleri bitişik ele almak gerektiğini, ayrı yazılmaları halinde birleşimi oluşturan sözcüklerin kendi anlamlarını çağrıştıracağını (Gencan, 1979, s. 247) ifade etmişlerdir. Ancak konuyu daha detaylı olarak ele alan müstakil makalelerde birleşik sözcüklerin yazımına dair farklı düşünceler bulunmaktadır.

Korkmaz birleşik sözcüklerin ne olduğu ve nasıl yazılması gerektiği ile ilgili kaleme aldığı yazıda², birleşik sözcüklerin yazımındaki tutarsızlıkların temel nedeninin birleşik sözcük tanımlarındaki farklı anlayışlar olduğunu ifade etmiştir. Birleşik sözcüklerin yeni kavramları adlandırmadaki önemine değinen ve bu sözcüklerin hangi yollarla oluştuğunu açlklayan Korkmaz, bitişik veya ayrı yazılma konusundaki kıstasın anlam değişmesi olması gerektiğini, birleşmelerde anlam değişmesi oluyorsa sözcüklerin bitişik; anlam değişmesi olmuyor ve birleşimi oluşturan unsurlar anlamlarını koruyorsa ayrı yazılması gerektiğini şu sözlerle ifade etmiştir: “... kendi anlamların değiştirmeden birbiri ile kaynaşarak yeni bir kavrama karşıllk olan birleşik kelimeler ayrı yazılır; eski anlamlarını kısmen veya tamamen kaybederek yepyeni bir anlam oluşturacak biçimde kaynaşmış bulunan birleşik kelimeler de bitişik yazılır şeklinde bir imlâ kurah koyar isek, o zaman, birleşik kelimelerin yazılışını, bunların niteliklerine uygun çok daha sağlıklı bir kurala bağlamış oluruz.” (Korkmaz, 2005, s. 636637).

Zülfikar, yazım kılavuzlarında birleşik sözcüklerin yazımı meselesini ele aldığı yazısında³ 1928 yılından günümüze kadar bu konu ile ilgili ortaya konulan görüşleri ifade etmiştir. Birleşik sözcüklerin bitişik veya ayrı yazılmasının 1928 öncesindeki Arap harfli yazı ile de ilgisi olduğunu, Türk Dil Kurumu'na farklı dönemlerde başkanlık yapan Türk dili araştırmacılarının görüş ayrılıkları nedeniyle yazım kılavuzunda değişmeler olduğunu ifade eden Zülfikar, ülke çapında bir yazım birliği olması adına bu sözcüklerin

\footnotetext{
2 Zeynep Korkmaz, "Birleşik Kelimeler ve Yazılışları Üzerine", Türk Dili Üzerine Araştırmalar I, Türk Dil Kurumu Yayınları, Ankara 2005, s. 632-637.

3 Hamza Zülfikar, "Yazım Kılavuzlarında Kelimeleri Bitişik veya Ayrı Yazma Sorunu", Türk Dili Dil ve Edebiyat Dergisi, 105. Cilt 742. Sayı, s. 29-38.
} 
yazımında Türk Dil Kurumu'nun yayımladığı Yazım Kılavuzu'nun esas alınması gerektiğini ifade etmiştir (Zülfikar, 2013, s. 38).

Birleşik sözcükleri ses, şekil ve anlam yönünden inceleyen Göğüş’ün çalışması bu konuyu kapsamlı bir şekilde ele almaktadır. Göğüş, birleşik sözcüklerin anlamca birleşmiş olduklarını, şekil olarak birleşik yazılmaları gerekmediğini belirtir. Birleşik sözcüklerin yazımına dair çözüm önerisini şu şekilde açıklar: “...bitişik yazılma yolunu, bileşik kelimelerden hattrda kalabilecek bir miktarna ve şekil, ses değişmeleri gibi belirtici özellikler taşıyanlara özgü kulı geri kalanlarmı ayrı yazmak daha uygun olur. Hattâ diyeceğiz ki, bileşik kelimelerin ayrı yazıldığımı kabul edip bitişik yazılacağı haller için kural koymak ve bunu açıkça ifade etmek gerekir.” (Göğüş, 1962, s. 261).

Birleşik sözcüklerin yazımı ile ilgili tüm tartışmaları ve görüşleri ortaya koyması, çeşitli yazım kılavuzlarında yer alan görüşleri sunması ve bu doğrultuda kendi önerilerini de teklif etmesi bakımından Koç’un makalesi 5 de bu hususta önemli bir yer tutmaktadır. Konuyla ilgili yıllardır yapılan tartışmaları ortaya koyup, çeşitli kılavuzlardaki yazım örneklerini veren Koç, birleşik sözcüklerin yazımında anlam değişmelerinin dikkate alınması gerektiğini, anlam kaybına uğrayan yapıların birleşik, anlam kaybı olmayanların ayrı yazılması gerektiğini ifade etmiştir (Koç, 2007, s. 706).

Yüceol Özezen ise birleşik sözcük sorununun yalnızca bir yazım sorunu olmadığını ifade eder. Ona göre, Türkçede birleşik sözcüklerin sıklıkla bitişik yazılma eğiliminde olması, birleşik sözcük oluşturmaya yarayan bazı sözcüklerin (alt, üst, ön, dış, iç vb.) önek veya önekimsi olarak gelişmekte olduğunu düşündürmektedir. Türkçenin tipolojisinde önek olmadığını ancak dillerin zaman içerisinde birbirinden etkilenerek tipolojik değişimler yaşayabileceğini ifade eden yazar, alt, üst, ön, dış, iç vb. sözcüklerin şu an için önek olmadı ̆̆ını ancak bu doğrultuda bir gelişim gösterdiğini belirtir ${ }^{6}$.

Birleşik sözcüklerin yazımı konusunda çok farklı görüşler bulunmakla birlikte, ülke çapında bir yazım birliği olması adına, bu konuda son söz sahibi olan Türk Dil Kurumu’nun ortaya koyduğu kurallar kişisel görüşlerin üzerindedir ve herkesi bağlamaktadır. Kurum'un çıkarmış olduğu en son Yazım Kılavuzu'nda birleşik sözcüklerin yazılışı ile ilgili ayrıntılı açıklamalar bulunmaktadır7. Bu açıklamalar incelendiğinde, birleşik sözcüklerin bitişik veya ayrı yazılması konusundaki temel kuralın ses veya anlam değişmesi olduğu görülmektedir. Ses veya anlam değişmesi olan birleşik sözcüklerin bitişik; olmayanların ise ayrı yazılması gerektiği söylenmiştir. Bunun haricinde bazı bitki, hayvan, yer, araç, gök cisimleri vb. adların yazımı ile ilgili de çeşitli kurallar verilmiştir. Ancak, belirtisiz ad tamlaması yoluyla oluşan birleşik sözcüklerde farklı durumlar meydana gelebilmektedir. Bu tür birleşik sözcüklerin bazıları tamlama özelliğini yitirmiş, bazıları ise devam ettirmektedir. Bu da, bu tür sözcüklerin yazımında ikili durumları ortaya çıkarmaktadır.

\section{Belirtisiz ad tamlaması biçiminde oluşan birleşik sözcüklerde yazım sorunu}

Belirtisiz ad tamlaması yoluyla oluşan birleşik sözcüklerde anlamca kaynaşma ve ses değişmeleri yönünden farklı durumlar görülmektedir. Anlamca tamamen kaynaşan veya ses düşmesine uğrayan sözcüklerde tamlama özelliği ortadan kalkmakta, kaynaşmanın tam olmadı̆̆ı ve ses düşmesinin

4 Beşir Göğüş, “Türkçede Bileşik Kelimelerin Oluşumu ve Nasıl Yazılması Gerektiği”, TDAY-Belleten, 1962, s. $245-264$.

5 Raşit Koç, "Türkçede Birleşik Kelimelerin Yazımı ile İlgili Tartışmalar ve Çözüm Önerileri”, Kastamonu Eğitim Dergisi, 2007, 15. Cilt 2.: Sayı, s. 693-706.

6 Muna Yüceol Özezen, “Türkiye Türkçesinde ‘Birleşik Sözcük' Sorunu Yalnızca Bir Yazım (İmla) Sorunu mudur?”, ed. Öztürk Emiroğlu, Marzena Godzinska \& Filip Majkowski, Türkoloji Tartışmaları (Başarı ve Zaaflarıyla Çağdaş Türkoloji), Warsaw 2014.

7 bkz. Yazım Kılavuzu, 27. bs., Türk Dil Kurumu Yayınları, Ankara 2012, s. 18-24. 
yaşanmadığı bazı örneklerde ise tamlama özelliği devam etmektedir. Örneğin ayakkabı (ayak kap+ı) sözcüğü belirtisiz ad tamlaması yoluyla oluşmuş bir birleşik sözcüktür. Ayakkabı birleşik sözcüğünü oluşturan ayak ve kap sözcükleri ayrı anlamlara sahip olmakla birlikte, ayakkabı birleşiminde ortak bir anlam kazanmışlar ve tek bir kavramı işaret eder hale gelmişlerdir. Bu birleşik sözcükte yer alan iki farklı unsurun anlamca tamamen kaynaştı̆̆ı ve bu sebeple de tamlama özelliğini yitirdiği görülmektedir.

Ses düşmeleri de birleşik sözcüklerdeki tamlama özelliğini ortadan kaldırmaktadır. Örneğin kahvaltı (kahve+altr), pazartesi (pazar+ertesi) gibi örneklerde ses düssmesi olmuş, bu sözcüklerde hem anlam hem de biçim yönünden bir kaynaşma meydana gelmiş ve tamlama özelliği ortadan kalkmıştır.

Bu sebeple de bu gibi oluşumlar dilde müstakil bir sözcük olarak kabul edilir. "ayakkabı, kahvaltı" türünden sözcükler ad tamlamasını çağrıştırmamakta, tamlamanın sonundaki iyelik eki işlevini yitirmektedir. Ayakkabı örneğinden hareketle, bazı birleşik sözcüklerdeki tamlama özelliğinin ortadan kalktığına ve tamlama sonundaki iyelik ekinin işlevini yitirdiğine dair bazı dil bilgisel deliller gösterilebilir:

1. Ayakkabı sözcüğünün sonuna çokluk eki olan $+l A r$ gelebilmektedir: $B u$ yüzden, ayakkabılarmm çıkarıp sessizliğin kenarma bıraktıktan sonra bir süre dikildim kapının ardında (Toptaş, 2001, s. 24). Bilindiği gibi Türkçe ad çekim eklerinin sözcüklere eklenme sırasında çokluk eki iyelik ekinden sonra gelmemektedir.

2. Ayakkabı sözcüğünün sonuna üçüncü kişi teklik iyelik eki gelebilmektedir: Bazı adamlarn kadınların / Aşk yürüne yürüne yıpranmış / Ayakkabısından havasından / Günde yaşamasından kurtulması (Akın, 1992, s. 72). Türkçede bazı istisnalar dışında aynı işleve sahip iki iyelik eki üst üste gelememektedir. "bir $+i+s i$, $k i m+i+s i$ " gibi örneklerde biri ve kimi sözcüklerinin kalıplaşması ve sonlarında yer alan iyelik ekinin işlevinin zayıflaması sebebiyle aynı işlevde iki iyelik eki üst üste gelmiş gibi görünmektedir. “ayakkabı” örneğinde de iyelik ekinin işlevi ortadan kalkmıştır.

3. Ayakkabr sözcüğünün sonuna herhangi bir hal eki eklendiğinde araya zamir n'si girmez. Bilindiği gibi üçüncü kişi teklik ve çokluk iyelik eklerinden sonra gelen hal eklerinde iyelik eki ile hal eki arasına zamir n'si gelir. Ayakkabı sözcüğünün sonunda yer alan iyelik eki işlevini yitirdiği için bu sözcüğe eklenen hal eklerinde zamir n'si görülmez: Yalnızhk kale kapısında / Fındık kabuğunda / Atılmış bir ayakkabıda çöpler arasında (Altık, 2014, s. 152).

$\mathrm{Bu}$ durumlar göstermektedir ki ayakkabr sözcügünde tamlama özelliği ortadan kalkmış, tamlama sonundaki iyelik eki, işlevini yitirmiştir. Ancak bu durum, belirtisiz ad tamlaması biçiminde oluşmuş birleşik sözcüklerin tümünde aynı değildir.

Belirtisiz ad tamlaması biçiminde oluşan bazı birleşik sözcüklerde, Türkçe ad çekim ekleri sıralanışı kuralının işlediği görülmektedir. Örneğin "başörtüsü” belirtisiz ad tamlaması biçiminde oluşmuş bir birleşik sözcüktür. Bu sebeple de sözlükte madde başı olarak ve bitişik halde ele alınmıştır8. Ancak bu birleşik sözcükte tamlama özelliğinin devam ettiği ve sonda yer alan iyelik ekinin işlevini yitirmediği görülür. Bu sözcüğe çokluk, iyelik ve hal eklerinin eklenme durumuna bakıldığında durum daha net anlaşlacaktır: 
The grammatical contradictions in the writing of the compound words that formed in the form of İndeterminative noun phrase / S. Toktar (p. 24-32)

1. Çokluk eki bu sözcüğe doğrudan doğruya eklenemez: Başörtülerini düzelttiler (Akın, 1992, s. 360).

2. Sözcüğün sonundaki iyelik eki işlevini yitirmediği için bu sözcüğe iyelik eki getirilemez: Başörtüsüm şeklinde bir kullanım mümkün değildir.

3. Sözcüğe hal eki getirildiğinde araya zamir n'si girer: Kaşına kadar indirdiği başörtüsünü düzeltti (Akın, 1992, s. 357).

Kavramsal olarak bakıldığında başörtüsü de tıpkı ayakkabı örneğinde olduğu gibi zihinde tek bir kavramı işaret etmektedir. Bu yönüyle kalıplaşmış bir yapı olduğu düşünülebilir. Ancak yukarıda bahsedilen dil bilgisel özellikler nedeniyle de bu yapının halen bir tamlama gibi işlem gördüğü ortadadır. Ayrıca başörtüsü sözcüğünde ne ses düşmesi ne de anlam değişmesi vardır. Birleşimi oluşturan unsurlar ayrı ayrı temel anlamlarını muhafaza etmektedirler. Öyleyse başörtüsü ve buna benzer yapıların gerçekten kalıplaşıp kalıplaşmadığını ve sözlükte madde başı olarak bitişik halde ele alınıp alınamayacağını sorgulama gereği doğmaktadır. Ayakkabı sözcüğünün kalıplaştığını, tek bir sözcük olarak algılandığını ve tamlama özelliğini yitirdiğini söylemek mümkündür. Ancak başörtüsü gibi yapıların zihinde tek bir kavramı işaret etmelerine rağmen dil bilgisel olarak henüz kalıplaşmadıkları ve tamlama olarak işlem gördükleri de ortadadır. Gencan da bu duruma değinmiş, çokluk ve hal eklerini doğrudan doğruya alabilen belirtisiz ad tamlaması türünden birleşik sözcükleri "tam kaynaşmış"; çokluk ve hal eklerini doğrudan alamayan, tamlama özelliğini devam ettiren birleşik sözcükleri ise "yarı kaynaşmış" olarak adlandırmıştır (Gencan, 1979, s. 247).

Özetlemek gerekirse, belirtisiz ad tamlaması biçiminde oluşmuş birleşik sözcüklerde iki farklı durum ortaya çıkmaktadır: 1. Tamlama özelliğini yitirmiş birleşik sözcükler, 2. Tamlama özelliğini devam ettiren birleşik sözcükler.

Tamlama özelliğini yitirmiş birleşik sözcüklerin sonuna ad çekim eklerinden herhangi biri getirildiğinde birleşik sözcüğün sonundaki iyelik eki işlevini yitirdiği için yazımda herhangi bir sorun oluşmamakta, ekler birleşik sözcüğe doğrudan eklenebilmektedir (ayakkabı > ayakkabılar, ayakkabıda vb.). Ancak tamlama özelliğini devam ettiren başörtüsü, cezaevi, zeytinyağı vb. birleşik sözcüklere ad çekim ekleri getirildiğinde, sözcüğün sonundaki iyelik eki işlevini koruduğu için sözcüklerin yazımında Türkçenin dil bilgisi kurallarına aykırı durumlar ortaya çımaktadır. En somut örnek olarak, bu türden bir sözcüğe getirilecek olan çokluk eki sanki sözcüğün sonuna değil de içine ekleniyormuş (aşevi > aşeviler yerine aşevleri) gibi bir görünümün ortaya çlkması gösterilebilir. Bilindiği gibi Türkçede içek (infix) yoktur. Ana dili Türkçe olan ve Türkçenin dil bilgisi kurallarına hâkim olan kişiler için bu durum anlaşılabilir olsa da, Türkçeyi yabancı dil olarak öğrenen kişilerde bu türden sözcüklerin yazımı karışıklığa sebebiyet verecektir.

\section{Sonuç}

Birleşik sözcüklerin yazımı meselesi Türkoloji alanında uzun yıllar tartışılmış ancak kesin bir sonuca varılamamıştır. Bu konuda son söz sahibi olan Türk Dil Kurumu birleşik sözcüklerin yazımı ile ilgili çeşitli kurallar ortaya koymuştur. Ancak Kılavuz'a bakıldığında, birleşik sözcüklerin yazımı konusunda bazı tutarsızlıkların olduğu da görülmektedir.

Yazım Kılavuzu'nda Bitişik Yazılan Birleşik Kelimeler başlı̆̆ının 3. maddesinde "kelimelerden her ikisi veya ikincisi birleşme sirasında anlam değişmesine uğradığında bu tür birleşik kelimeler bitişik yazılır (Yazım Kılavuzu, 2012, s. 18)" şeklinde bir açıklama bulunmaktadır. Bununla birlikte aynı başlığın 14. 
maddesi 3. maddede yer alan kuralla çelişir görünmektedir. 14. maddede geçen "dilimizde her iki ögesi de asıl anlamın koruduğu halde yaygın bir biçimde gelenekleşmiş olarak bitişik yazılan kelimeler de vardır (Yazım Kılavuzu, 2012, s. 20)" ifadesi 3. maddede verilen kurala uymamaktadır. Yaygın bir biçimde kullanılma ve gelenekleşmiş olma, birleşik sözcüklerin nasıl yazılması gerektiği konusunda bilimsel bir gerekçe olarak görülemez. Birleşik sözcüklerin niçin bitişik yazılması gerektiği, dil bilgisel bazı gerekçeler ile açıklanmalıdır. Örneğin, herhangi bir ses ve anlam değişmesine uğramamış ve belirtisiz ad tamlaması biçiminde oluşmuş olan zeytinyă̆ (Yazım Kılavuzu, 2012, s. 581) bitişik yazılırken tamamen aynı şekilde oluşmuş gül yăğ (Yazım Kılavuzu, 2012, s. 268)'nın neden ayrı yazıldığı belli değildir. Bu iki birleşik sözcük arasında dil bilgisel ve anlamsal olarak herhangi bir ayrım bulunmamaktadır.

Belirtisiz ad tamlaması biçiminde oluşmuş birleşik sözcüklerin yazımında bu gibi tutarsızlıklara sıkça rastlanmaktadır. Bu tür birleşik sözcüklerde tamlama özelliğinin devam edip etmemesi durumu da yazımda bazı aykırılıklara yol açmaktadır. Tamlama özelliğini devam ettiren birleşik sözcüklerde tamlama sonunda yer alan iyelik eki işlevini korur. Tek bir sözcük gibi düşünülen bu yapılara herhangi bir ek gelmesi durumunda Türkçenin dil bilgisi kurallarına aykırı durumlar ortaya çıkmaktadır. "kahvaltı, pazartesi vb." türden birleşik sözcükler ses değişmesi sebebiyle, "akşamsefası, hanımeli vb." türden birleşik sözcükler ise anlam değişmesi sebebiyle bitişik olarak yazılmaktadır. Ancak başörtüsü, zeytinyağı, cezaevi vb. birleşik sözcüklerde ses ve anlam değişmesi olmamakla beraber bu yapılar tamlama özelliğini de devam ettirmektedir. Bu türden yapıların tamlama özelliklerini devam ettirdiklerini anlayabilmek için sonlarına ek getirmek yeterlidir. Örneğin bu yapıların çokluk hallerinin başörtüsüler, zeytinyağılar, cezaeviler yerine, başörtüleri, zeytinyağları, cezaevleri biçiminde kurulması tamlama özelliklerini koruduklarının, tamlama sonundaki iyelik ekinin işlevini devam ettirdiğinin ve bu yapıların tek bir sözcük gibi düşünülemeyeceğinin kanıtıdır.

Herhangi bir ses ve anlam değişmesi yaşamayan ve tamlama özelliğini de devam ettiren başörtüsü, zeytinyağı, cezaevi vb. birleşik sözcüklerin yazımı ile ilgili Yazım Kılavuzu'nda daha kesin kurallar ortaya konmalı, bu kurallar doğrultusunda, Türkçe Sözlük'te madde başı olarak yer alan ve belirtisiz ad tamlaması biçiminde oluşan birleşik sözcüklerin yazımında tutarlılık sağlanmalıdır. Bu türden yapıların yazımda ayrı olarak ele alınmasının yukarıda bahsedilen aykırılıkların önüne geçeceği düşünülmektedir.

\section{Kaynakça}

Akın, G. (1992). Seyran (Toplu Şiirler). İstanbul: Adam Yayınları.

Altıok, M. (2014). Bir Acıya Kiracı (4. b.). İstanbul: Kırmızı Kedi Yayınevi.

Banguoğlu, T. (2015). Türkçenin Grameri (10. b.). Ankara: Türk Dil Kurumu Yayınları.

Ediskun, H. (2017). Yeni Türk Dilbilgisi (13. b.). İstanbul: Remzi Kitabevi.

Ergin, M. (2009). Türk Dil Bilgisi. İstanbul: Bayrak Basım/Yayım/Tanıtım.

Gencan, T. N. (1979). Dilbilgisi. Ankara: Türk Dil Kurumu Yayınları.

Göğüş, B. (1962). Türkçede Bileşik Kelimelerin Oluşumu ve Nasıl Yazılması Gerektiği. TDAY-Belleten, 245-264.

İmer, K., Kocaman, A., \& Özsoy, A. S. (2011). Dilbilim Sözlüğü. İstanbul: Boğaziçi Üniversitesi Yayınları. Karaağaç, G. (2013). Dil Bilimi Terimleri Sözlüğü. Ankara: Türk Dil Kurumu Yayınları.

Koç, R. (2007). Türkçede Birleşik Kelimelerin Yazımı ile İlgili Tartışmalar ve Çözüm Önerileri. Kastamonu Ĕ̈itim Dergisi, 15(2), 693-706.

Korkmaz, Z. (1992). Gramer Terimleri Sözlüğü. Ankara: Türk Dil Kurumu Yayınları. 
The grammatical contradictions in the writing of the compound words that formed in the form of Indeterminative noun phrase / S. Toktar (p. 24-32)

Korkmaz, Z. (2005). Türk Dili Üzerine Araştırmalar I. Ankara: Türk Dil Kurumu Yayınları.

Korkmaz, Z. (2014). Türkiye Türkçesi Grameri Şekil Bilgisi (4. b.). Ankara: Türk Dil Kurumu Yayınları.

Toptaş, H. A. (2001). Ölü Zaman Gezginleri. İstanbul: Adam Yayınları.

Türkçe Sözlük (11. b.). (2011). Ankara: Türk Dil Kurumu Yayınları.

Yazım Kılavuzu (27. b.). (2012). Ankara: Türk Dil Kurumu Yayınları.

Yüceol Özezen, M. (2014). Türkiye Türkçesinde "Birleşik Sözcük" Sorunu Yalnızca Bir Yazım (İmla) Sorunu mudur? Ö. Emiroğlu, M. Godzinska, \& F. Majkowski içinde, Türkoloji Tartışmaları Başarı ve Zaaflarıyla Çağdaş Türkoloji (s. 748-758). Warsaw.

Zülfikar, H. (2013). Yazım Kılavuzlarında Kelimeleri Bitişik veya Ayrı Yazma Sorunu. Türk Dili Dil ve Edebiyat Dergisi, 105(742), 29-38. 